\title{
is Research Square \\ Implementation Evaluation of A Secondary Level Whole School Programme: A Qualitative Inquiry
}

Fiona McHale ( $\nabla$ fiona.mchale@ul.ie )

University of Limerick https://orcid.org/0000-0003-2997-2412

\section{Kwok Ng}

University of Limerick

Jemima Cooper

University of Bath

Dylan Scanlon

Dublin City University

Caera Grady

University of Limerick

Catherine Norton

University of Limerick

Donal O'Shea

University College Dublin

Catherine Woods

University of Limerick

\section{Research}

Keywords: programme, barriers, implementation, strategies

Posted Date: November 16th, 2021

DOI: https://doi.org/10.21203/rs.3.rs-1044967/v1

License: @ (i) This work is licensed under a Creative Commons Attribution 4.0 International License. Read Full License 


\section{Abstract}

Background: Whole-of-school programmes (WSPs) are one of eight best investments to reduce physical inactivity. The 'Secondary Level Active School Flag' (SLASF) programme for students aged 12-19 years is one such WSP for physical activity. This student-led programme is guided by student voice, fun, inclusiveness and partnerships. Due to the complexities of the school system and the multi-component nature of WSPs, there is a risk of poor implementation. The monitoring of facilitators and barriers as unanticipated influences during feasibility studies is important to better understand the key implementation processes prior to scale-up. The aim of this study was to identify perceived facilitators and barriers to implementing the SLASF. Guided by the ERIC taxonomy, it also aimed to select and recommend evidence-based implementation strategies to overcome the barriers and leverage programme facilitators.

Methods: Process evaluation focus groups $(\mathrm{N}=22)$ and interviews $(\mathrm{N}=27)$ were conducted in three schools with programme implementers i.e. school management $(n=5)$, SLASF coordinator $(n=4)$, student-leaders (ASF transition years aged 15-16 years) class $(n=37)$, staff committee $(n=23)$ and were transcribed verbatim. Transcripts were analysed using reflexive thematic analysis and were guided by the Consolidated Framework for Implementation Research. Implementation strategies were identified using the ERIC taxonomy and were selected systematically to address contextual needs.

Results: Three themes were identified surrounding the facilitators and barriers to implementation: intervention design factors influencing implementation (e.g. capacity building and knowledge of implementers; interest and buy in for the programme and design and quality of the programme), organisational factors influencing implementation (e.g. optimisation of people; planning and execution; and the busy school environment) and interpersonal factors influencing implementation (e.g. relationships; communication; and collaboration).

Conclusions: This study has identified drivers of implementation success or failure for future impact and extended roll out of SLASF. The examination of facilitators and barriers assisted with the identification of implementation strategies including (not limited to) a shared leadership programme for student leaders, a more flexible timeline for completion and an introductory year to assess readiness to engage. Through guidance on the identification of implementation strategies and in alignment with the ERIC taxonomy, we have provided recommendations that may assist in effective implementation of the SLASF.

\section{Contributions To The Literature}

- To the author's knowledge this is the first study to examine the facilitators and barriers to implementation of a school-based physical activity (PA) whole-of-school programme (WSP).

- This comprehensive qualitative inquiry guided by the Consolidated Framework for Implementation Research (CFIR) establishes key implementation processes that will assist programme developers in addressing implementation challenges and leverage programme facilitators.

- Aligned with the Expert Recommendations for Implementing Change (ERIC) taxonomy, we recommend implementation strategies to assist in the ongoing development of the SLASF e.g. educational meetings, identifying and preparing champions, creation of a learning collaborative etc. 


\section{Introduction}

Physical inactivity is one of the leading causes of global mortality (1) and despite the unequivocal evidence of the benefits of physical activity (PA), $84.7 \%$ of girls and $77.6 \%$ of boys globally are insufficiently active (2). Adolescence is a critical period where physical inactivity has adverse effects physically, socially and mentally (3-5) and behaviours learned during adolescence tracks into adulthood (6).

Adolescents spend majority of their waking hours in school, thus, is an appropriate environment to effect change in lifestyle choices and habits, providing opportunities to reach students of various socio-demographic backgrounds $(7,8)$. The most recent school-based PA promoting programmes have shown little to no effectiveness for increasing MVPA levels in adolescents $(9,10)$. One possible explanation for the lack of efficacy may be that schools are unique, complex adaptive sub-systems (11) resulting to difficulties in implementation of such interventions $(10,12)$.

The International Society for Physical Activity and Health's (ISPAH) eight best investments for reducing physical inactivity (13) include whole-of-school programmes (WSPs), furthermore supported by the Global Action Plan on Physical Activity (GAPPA), highlighting the need to strengthen the provision of WSPs (14). WSPs for PA should be enabled by supportive school policies (15) targeting activity before, during and after school, as part of learning in the classroom and through active transport, engaging staff, parents and the wider community (13). As the literature and interest in WSPs for PA continue to develop, it is imperative to establish a greater understanding of their implementation, particularly at secondary school level (16). In Ireland, the Active School Flag (ASF) is a Department of Education and Skills (DES) WSP (17) that aims to get schools more active more often (16). This programme was successfully implemented at primary school level (approx. 6-12y olds) where $46 \%$ of all Irish primary schools have completed the programme (18) compared with just $5 \%$ of secondary level schools (17). Although there has been limited research on the effectiveness of ASF on MVPA levels, a pilot study ( $n=3$ primary schools) reported a significant effect on in-school MVPA (18).

Cognisant of implementation barriers and through formative work with the research team, the Irish DES and a youth-advisory panel the modified ASF programme underwent a feasibility trial and was called the Secondary Level Active School Flag (SLASF) programme (17). The formative work addressed acknowledged barriers to implementation and introduced a 2-year programme focused on improving PA opportunities in the school (year 1) and in the community (year 2). Elements included a PA champion in the school (the ASF coordinator), active involvement of school management, identification of a designated class of students (ASF transition year (TY) class) and a staff committee (17). TY is a is a non-academic "gap" year unique to Ireland between the first and second set of formal exams with the aim of promoting students' social and personal development (19). As illustrated in Figure 1, the SLASF was implemented through the school by these programme implementers (ASF coordinator, ASF TY students, school management and ASF committee) with the aim of reaching students, staff, the community and parents (20). The ASF coordinator, supported by a staff committee (to include a member of school management), was responsible for championing the programme in the school, leading on events and facilitating the ASF TY class with programme leadership. The ASF TY class were the class responsible for leading ASF among the student body through promoting and assisting in running events and programme tasks.. This SLASF programme is underpinned by student voice with the aim of providing students with agency and being actively involved in change (21). The long-term aim 
of the Irish DES is to achieve national roll out of the SLASF in all secondary level schools in Ireland (e.g. rural, affluent, disadvantaged, single sex and co-educational).

Due to the complexities of school-based PA programmes they are vulnerable to poor implementation (22) reducing their chance of positive outcomes (23). Therefore, there is a need for research to focus on understanding the implementation process of such complex interventions (10). The Consolidated Framework for Implementation Research (CFIR) is an determinant framework that captures the complex, multi-level nature of implementation in settings $(24,25)$. This framework suggests that intervention implementation is influenced within five domains: intervention characteristics, the outer setting, the inner setting, the characteristics of the individual and the process of implementation that interact in rich and complex ways for successful implementation (26). The identification of facilitators and barriers to implementation is the top use of implementation frameworks and theories (27) and can be used to inform adaptations of the innovation, implementation, scale-up or programme sustainability (28). The monitoring of facilitators and barriers as unanticipated influences during feasibility studies is important to better understand the key implementation processes prior to scale-up (26). Additionally, implementation data is vital to ascertain the precise aspects of the programme impacting optimal implementation to interpret outcome data (23). Understanding the facilitators and barriers to programme implementation and subsequently providing solutions to these barriers and leveraging the facilitators to maximise and sustain uptake is essential for programme success (29).

An implementation strategy is a technique used to enhance the adoption, integration, implementation and sustainability of an evidence-based intervention into routine care $(30,31)$. These 'how to' components are considered strategies to overcome barriers and increase the pace and effectiveness of the intervention (32). In order to provide useful implementation strategies to schools implementing the SLASF, more understanding of how this WSP can fit into the secondary school context is required. A refined compilation of implementation strategies such as this Expert Recommendations for Implementing Change (ERIC) taxonomy have standardised the identification, naming and definition of implementation strategies and have made them more translatable and consistent with other implementation research (33). To design and execute these implementation strategies, factors which may influence these implementation outcomes and determinants are needed $(30,34)$.

Therefore, the aim of this investigation was to i) identify perceived facilitators and barriers to implementing the SLASF and ii) through the use of the ERIC taxonomy, identify and recommend evidence-based implementation strategies to overcome these challenges.

\section{Methods}

\section{Study design and research paradigm}

A qualitative approach was used to collect data and understand the complexities associated with implementing the SLASF in the secondary school setting and within diverse contexts (35). This study adds value to implementation science through providing a rigorous and efficient way to describe what is happening, how and why, assisting in problem solving and supporting practice (36). Focus groups and interview discussions were used as they are a useful method in studies aiming to describe peoples' experiences and 
encourage in depth discussion especially when exploring the ideas and perspectives of young people $(37,38)$. The CFIR guided the data analysis and assisted in interpreting the findings (26). Through use of such a framework as the CFIR and engagement with schools to examine their perceived facilitators or barriers in programme implementation, school stakeholders can assist in the development of appropriate and contextually-relevant implementation strategies (39).

\section{Sample selection, recruitment and ethics}

Ethical approval was granted by the ethical research committee of <blinding purposes> University as part of the SLASF programme. All ASF implementers from the three SLASF schools were purposively sampled to yield information-rich data on programme implementation (40). Details of the study participants is in Table 1.

Table 1

Breakdown of study participants

\begin{tabular}{|c|c|c|c|c|c|c|c|}
\hline School & Type & Setting & $\begin{array}{l}\text { DEIS } \\
(Y / N)\end{array}$ & $\begin{array}{l}\text { ASF } \\
\text { coordinator }\end{array}$ & $\begin{array}{l}\text { School } \\
\text { management }\end{array}$ & $\begin{array}{l}\text { ASF staff } \\
\text { committee }\end{array}$ & $\begin{array}{l}\text { ASF } \\
\text { TYS }\end{array}$ \\
\hline 1 & Girls & Urban & $\mathrm{N}$ & $n=1(1 f)$ & $n=2(2 f)$ & $n=6(6 f, 0 m)$ & $\begin{array}{l}n=22 \\
(22 f)\end{array}$ \\
\hline 2 & Mixed & Rural & $N$ & $n=1(1 f)$ & $n=2(1 \mathrm{f}, 1 \mathrm{~m})$ & $n=4(2 f, 2 m)$ & $\begin{array}{l}n=(9 f, \\
9 m)\end{array}$ \\
\hline \multirow[t]{2}{*}{3} & Mixed & Urban & Y & $n=3(2 f, 1 m)$ & $n=1(1 f)$ & $n=3(2 f, 1 m)$ & $\begin{array}{l}n= \\
(14 \mathrm{f}, \\
10 \mathrm{~m})\end{array}$ \\
\hline & & & & $\mathrm{N}=5(4 \mathrm{f}, 1 \mathrm{~m})$ & $\mathrm{N}=6(5 \mathrm{f}, 1 \mathrm{~m})$ & $\begin{array}{l}\mathrm{N}=13(10 \mathrm{f} \\
3 \mathrm{~m})\end{array}$ & $\begin{array}{l}N=58 \\
(45 f \\
19 m)\end{array}$ \\
\hline
\end{tabular}

Data retrieved from the Department of Education website.

$\mathrm{f}=$ female, $\mathrm{m}=$ male, $\mathrm{ASF}=$ Active School Flag, $\mathrm{TY} s=$ transition years, DEIS=Delivering Equality of Opportunity in Schools, $\mathrm{Y}=\mathrm{yes}, \mathrm{N}=\mathrm{no}$

\section{Data Collection}

Interview and focus group discussions took place at various time points across two academic years (Figure 2). A semi-structured interview script was used (Additional file 1) to explore the facilitators and barriers influencing the implementation of the programme. Flash cards were used in focus groups for some questions to allow participants to make choices and participate in decisions in a supportive environment where they feel they can speak out (44). All interviews were conducted by the first author a white Irish female, previously a physical education teacher undertaking a PhD in the area of PA and health for adolescents. Because the researcher was the main point of contact throughout the two years with the school for all aspects of the research project, a good rapport was developed with participants.

The study methods and reporting have been completed in accordance with the Standards for Reporting Qualitative Research (SRQR) (Additional file 2) (41). Interviews lasted on average 53 minutes. Focus groups were conducted with groups of four to eight participants and lasted on average 49 minutes. Overall, 27 
interviews and 22 focus groups took place over two academic years. See Table 2 for a breakdown of interviews and focus groups that took place.

Table 2

Summary of focus group and interview recruitment and composition

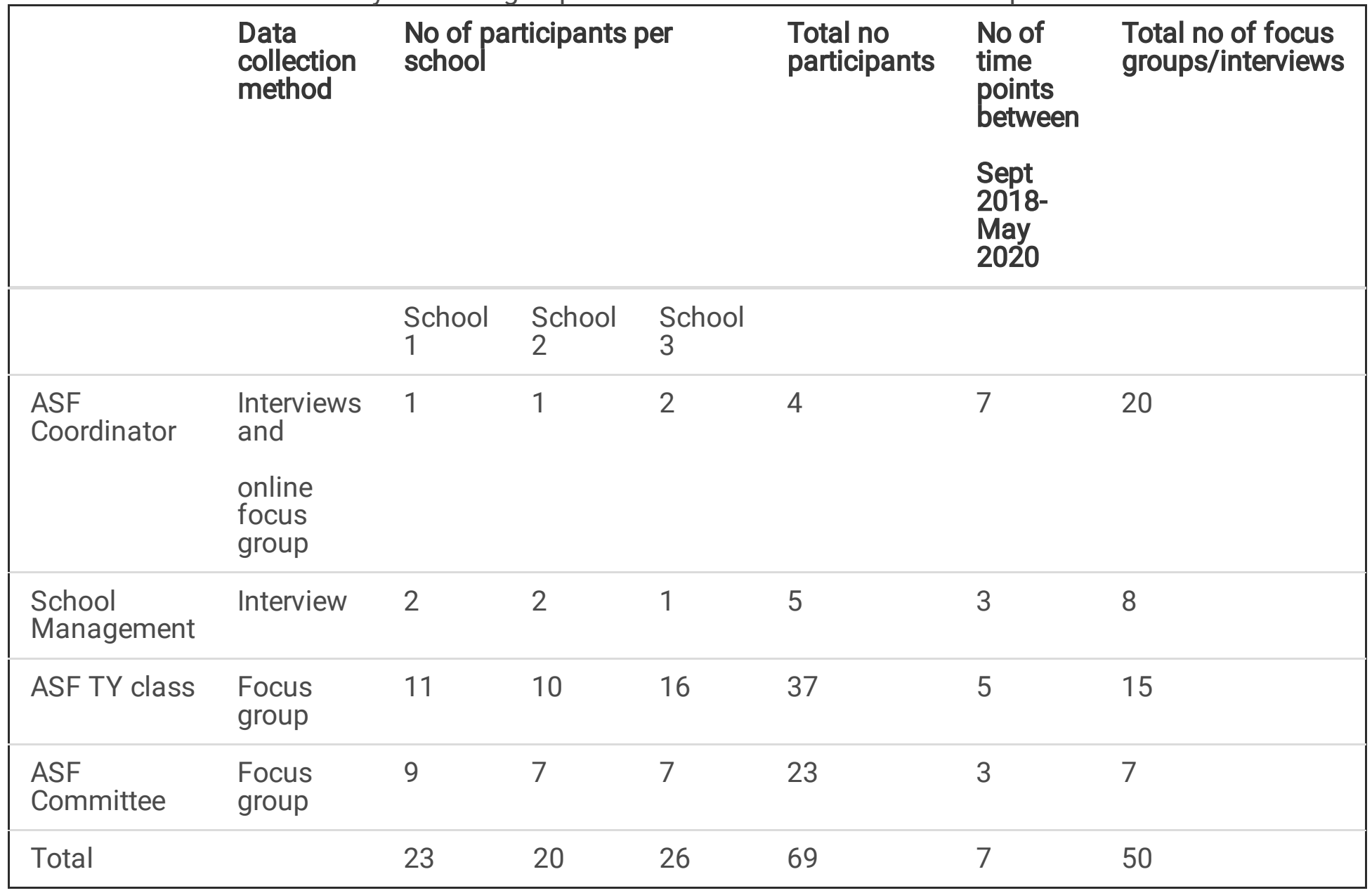

\section{Data analyses}

All interviews and focus groups were audio recorded with a digital recorder and a camcorder (without video) and transcribed verbatim. Data were imported into NVivo (QSR Version 12.0) to manage and organise the content initially and for the researcher to use for coding all data items.

Data were analysed using a reflexive thematic analysis (TA) (42) and supported by steps for TA to ensure rigour and validity of data collection and analysis (43). Through the guidance of Braun and Clarke's six phases to TA, the author took a recursive approach, acknowledging that these steps are not linear and require revisiting throughout the analysis (44). Thus, providing a framework for an inductive-deductive approach (45). The first author familiarised themselves with the data by (re-)listening and (re-)reading the interview transcripts. Guided by Elias' (1987) concept of involvement-detachment a team of six researchers supported each stage of the analysis (46). The team members included those who could provide a 'detached' perspective on the project (i.e., not directly involved in the planning or data collection phases) (46) and added credibility of the analysis and findings by engaging in researcher triangulation in this way (47). All six researchers initially 
coded one transcript each, coding for facilitators and barriers to implementation of SLASF using a data driven inductive approach. Each coded barrier or facilitator was put up on a "Padlet" (additional file 3-example of coding process), a cloud-based real-time collaborative web platform, and were subsequently coded deductively to one of the five CFIR domains: 'intervention characteristics', 'characteristics of individuals', 'inner setting', 'outer setting' and 'process of implementation' (26). A deviant case heading was also created and interpretations were openly discussed and challenged to achieve consensus.

Similar codes were merged within each domain through discussions and an initial codebook was created by the first author from this activity, providing an example of a previously identified code and a thorough description of the code (48). The codebook was entered onto NVivo as a starting point to the analysis and the remaining transcripts were coded (first author) using the same steps as outlined previously. Additional codes were added to the codebook throughout this phase. Once all data were coded, refined codes were developed [first author], combining these with all others across all five domains of the CFIR. The first author used interpretive judgment, assisted by critical probing from the research team, to construct themes from the initial and refined codes in an iterative manner (44). The research team acted as 'critical friends' (49) and (implicitly and explicitly) encouraged the first author to be reflective throughout the construction process (40). Two themes were generated from six sub themes and 22 refined codes. Generated themes were reviewed with the research team on multiple occasions and themes were named and renamed based on these critical friends' discussions.

Following the assessment of factors (facilitators and barriers) that influence implementation processes through stakeholder feedback and participation, implementation strategies were selected. Guided by Powell (2017) and using the CFIR, context specific implementation strategies were selected to alleviate barriers and leverage facilitators. These implementation strategies have the potential to address the context-specific factors identified pre-programme scale up and implementation (50).

\section{Results}

In the SLASF schools, multiple factors contributed to intervention implementation and these centred around three principal themes corresponding to 'intervention design factors influencing implementation', 'organizational factors influencing implementation', and 'interpersonal factors influencing implementation'. Participants discussed both facilitators and barriers within these three overarching themes.

\section{Theme 1: Intervention design factors in implementation of the SLASF programme}

\section{Intervention design facilitators}

In the participating schools 'acceptability of the design and quality of the ASF intervention', 'progression and momentum of ASF', 'acknowledgement that ASF needs time to see change' and 'provision of capacity building for implementers' were key facilitators of the intervention design. Schools gained 'momentum' when there was a feeling of success or progress in aspects of ASF including times where ASF was being promoted in the Active Schools Week (ASW). All coordinators and staff committee members acknowledged the learning that 
took place after year 1 completion and having a second year to act upon and build on this learning was deemed beneficial.

"I suppose I feel like maybe because it's starting to become part of our school life here, that people are now coming to me and asking me how they can be more, or how they can get more active in terms of their classes or in different events they're having. So, I feel like last year was always a hard sell for me and I was somebody who was constantly annoying people, whereas this year it's kind of we've turned a corner." (Coordinator, S1, Nov 2019)

Aspects of the design and quality of the intervention were key facilitators in implementation. The data suggests that stakeholders benefited from ASF through improved skills for the TYs, enjoyment for all stakeholders and a sense of accomplishment for all implementers.

"It had a positive impact, in that the kids are out and they're running around for 20 minutes on their break, rather than sitting down. I actually do think that it benefits teaching and learning in the classroom, because they're using up that energy that they have, that they normally use for annoying teachers, or being bold in class basically." (Coordinator S3, May 2020)

Some key features of the programme were having an element of competition at class or peer level, having a defined ASF class structure for TYs and other positive features such as the usability of ASF resources provided such as the ASF booklet and logbook.

\section{Intervention design barriers}

In the participating schools 'limited capacity and knowledge of implementers' and 'lack of interest or buy in for ASF' were barriers to implementation. Participants referred to ASF not gaining the interest of senior students, however they also referred to the fact that senior students had less of an opportunity than others to engage in the programme. The lack of involvement from senior students with ASF or in PA in general was an accepted phenomenon in schools and younger years were often easier to focus on for ASF.

Some implementer's lack of engagement and buy-in for their role was also referred to, particularly when ASF TYs who were randomly assigned to the ASF TY class.

"I just think it really comes down to the students you're working with. If I was working with a really good group of students, potentially we would be able to achieve all of the tasks. But who's going to know that in any year in any school?" (Coordinator S1, Feb 2020)

For committee members, not having the ASF class on their timetable acted as a barrier as this led to a limited involvement overall and a subsequent disconnect with the process. Not having an official time for the committee to meet and not having enough time to focus on certain aspects of the process were also perceived barriers.

"We don't have space or time, to kind of say, "Here's what we did and here's what we achieved. So it will be next September again when [the coordinator] is going to stand up or you [researcher] or whoever is going to come in and chat to our staff." (Management S1, May 2019) 
Overall, coordinators did not have the capacity in their working week to solely focus on ASF. Due to the workload of ASF and associated pressures, all coordinators referred to having tough moments throughout the process, a feeling that they were the only school struggling and not fully knowing what was ahead of them.

"There's only so many e-mails I can say, there's only so many times I can send. There's only so many times I can stand up in front of staff and be like, "Hey, everybody." There's only so many times that you can do it without feeling dejected or... you know." (Coordinator S3, Feb 2020)

There was a lack of skills in ASF TY students in the form of communication, leadership, organisational and planning for the tasks they were intended to implement. This impacted the implementation of student voice and student leadership approaches. A lack of awareness or familiarity with ASF was seen through some implementers for not being familiar with aspects of the programme. The fact that the process was not broken down at the start for the ASF TY class, coupled with not being given as much responsibility as others, subsequently led the ASF TYs to underestimating their value in the overall process.

"There's not as much student control as it's [SLASF] said there is. It's said all of the students organize the plan but it's really the teachers that plant the idea in the student's head and then we have to follow what the teachers tell us to do. But they [teachers] try to pass it off as it's us that's doing it."(ASF TY Boy S2, Feb 2020)

ASF TYs also referred to frustrations around the lack of shared workload in the class where some were pulling their weight more than others as reflected on by one ASF TY student in getting 'fed up with seeing the same people all the time'. In two schools, ASF TYs discussed not 'doing' enough in the class and too much talking and sitting around with much of the direction coming from the coordinator and instead of working towards tasks together, they were 'sitting there getting agitated'.

\section{Theme 2: Organisational factors in implementation of the SLASF programme}

\section{Organisational facilitators for ASF implementation}

Key areas acting as facilitators included 'optimisation of existing strengths', 'provision of time for implementers', 'good planning and execution' and 'optimisation of people'. A consistent finding was that good planning and execution assisted in implementation where implementers discussed being practical in their approach to running the programme. This included linking ASF with existing good practice in the school and the provision and attainment of resources necessary for ASF implementation such as the use of rewards, fundraising, development of long-term resources etc.

The optimisation of existing strengths involved tapping into previous experiences, merging ASF with existing practice, linking ASF with other initiatives going on in the school. ASF's link with the wellbeing curriculum was perceived as important for creating curriculum links as well as receiving support and buy in from teachers and management. Provision of time was mentioned as "the most valuable asset we have" for programme implementers was also a perceived facilitator whereby the coordinator had enough time with the ASF TY class through timetabled hours and a facilitated time for committee members to meet. 
The optimisation of people involved delegation of ASF related work to other members of staff and involvement and utilisation of a staff committee.

"Active Schools, particularly, was good because it's another branch of independence because ... [our teacher] trusts us to know what we are supposed to be doing in that class and we get to go off in our groups and do it. Like he said it's not just sitting down and learning something, you're actually working." (ASF TY girl S3, Dec 2019)

Facilitators also included empowering the ASF TY class members and allowing them to enact ASF implementation through class visits, announcements and involvement in the organisation of various ASF activities and events.

\section{Organisational barriers for ASF implementation}

Key areas acting as barriers included 'fitting a programme into an already busy school', 'the existing cultural context of the schools', 'poor optimisation of people' and 'poor optimisation of resources.' Throughout the leadership structures of ASF, stakeholders discussed a lack of delegation of responsibilities and empowerment of key implementers (ASF TYs and staff committee members). Additionally, committees had no designated time to meet and the workload fell back on the coordinator.

Within the cultural context of the schools, existing policies and procedures restricted the implementation of ASF at times. This occurred through social media and phone usage policies, uniform policies and PE provision at senior cycle. Moreover, taking on lots of initiatives was common to all schools and trying to fit ASF within these other programmes was perceived as a barrier by staff implementers.

"I also have to acknowledge that staff are stretched. They're just stretched. And I also think because in our school we do stuff where we throw it out there at the beginning of the year and give the overview or whatever else. And then by January, everyone's super-duper busy cause you're coming into mock time and you're finishing off Christmas exams. And that should be the midway point where you reflect and review and everything else. (Management S1, May 2019)

The busy school environment was a barrier with many competing priorities in the school, most notably teaching and learning. Additionally, aspects of the overall ASF programme required time commitment and staff implementers were often heavily involved in other initiatives.

\section{Theme 3: Interpersonal factors in implementation of the SLASF programme}

\section{Interpersonal facilitators to ASF implementation}

Key areas acting as facilitators included 'positive relationships among stakeholders', 'good communication about ASF within the school', 'efficient collaboration between stakeholders and departments' and 'a supportive climate for ASF'.

Delivering ASF through utilising communication channels, collaboration between departments, and positive relationships within a supportive climate assisted in programme implementation. A supportive climate 
encompassed support from management and staff in the daily running and logistics of the programme.

"I suppose it's going to be really important that we can relay the importance of what we want to happen on the [academic] timetable now. So l'd have to take a role in helping [the coordinator], not argue for what [they] want, but fight for the areas that they're looking for, to help [them], support [them]."(Management S1, Nov 2019)

Having good communication through multiple and relevant approaches was discussed by stakeholders as a facilitator to achieve reach within ASF in the schools. Additionally, effective communication channels between implementers assisted in a smoother running of the programme. Collaboration between departments to align ASF with existing ongoing initiatives was also a facilitator. Additionally, collaboration (mainly phone calls between ASF coordinators) between participating schools was a facilitator in year 2 where schools became more open to providing each other with support and advice on tasks as well as their general ASF journey. This was in comparison to year 1 where there were fears of being behind others in the process and lack of collaboration.

\section{Interpersonal barriers to ASF implementation}

Sub-themes barriers included 'poor collaboration between stakeholders around ASF', 'poor communication and clarity around ASF for stakeholders' and 'a lack of support for ASF'.

For all ASF coordinators, a lack of support was a perceived barrier. This included a lack of support from management and staff. Barriers cited included staff not replying to emails, not relaying ASF information to their students and a lack of value by important allies in the process such as the PE department (in one school). On occasions, the support from management was low in all three schools, fluctuating across the 2 years and 'depending on the ask'.

Poor and ineffective methods or lack of communication were perceived barriers and this was linked with a lack of awareness around ASF in the school. Additionally, there was poor communication between individuals implementing ASF. Within the school, it was felt that, implementers were not making the most of networks in the process ASF. This included a disconnect between those running the programme and the rest of the school and a lack of collaboration with other relevant groups or departments in the school. Additionally, the "why" of ASF was not reaching the wider school community.

"So you had four people there who were doing a lot, and it was a lot of initiatives at the moment at the same time, and I just, I suppose I felt, "At least they're really busy as it is, I don't want to be annoying them," and they never really asked me to do anymore because I'm on the TY committee, as well and the [member of committee] kind of left me alone, and I left them alone with it, because we were aware that we were really busy." (Coordinator S2, May 2019)

Themes and sub themes are illustrated in the thematic map (Figure 3), demonstrating that facilitators and barriers spanned all five domains of the CFIR. Codes and refined codes aligned with the five domains of the CFIR. This process identified that some sub themes were in just one domain for example 'existing cultural context of the school' and 'acknowledgement that ASF takes time to see change' were both identified in the inner setting only. However, the interaction of facilitators and barriers across multiple domains was also 
identified as exemplified by 'lack of interest, support and buy in for ASF' in the inner setting, intervention characteristics and characteristics of individual domains.

Guided by this data and the ERIC taxonomy, recommendations for implementation strategies to support some of these challenges have been made and are described in Table 3 and are discussed in the proceeding section (33). 
Table 3

Recommendations for implementation strategies for ASF and alignment with the ERIC taxonomy

\section{Implementation support strategy}

Addition of a readiness to engage document for management and staff

Addition of an introductory/readiness

"try it out" year to identify if school can/wants to proceed with the ASF programme

\section{Alignment with ERIC taxonomy \\ Objective of implementation strategy's influence on the SLASF programme}

(Plan) Assess

for readiness

and identify

barriers and

facilitators the programme before commencement.
Assesses for implementation readiness and commitment to

Introductory year identifies if school can/wants to proceed with the SLASF programme. Should also allow for schools to identify whole school motivation to deliver on the SLASF objectives, thus identifying their implementation capacity. This year would involve schools trying out fewer elements of the programme and putting structures in place i.e. staff committee, ASF TY timetabled class as well as a taster in administering the ASF survey to the whole student body.
Introduction of a userfriendly summary of whole school survey results

Collaboration between schools to share knowledge and provide support through online meetings and social media accounts e.g. twitter
Audit and provide feedback

Capture and share local knowledge
A user-friendly summary of survey results allows for ASF TY students to monitor student behaviours.
Addition of support webinars for different aspects of the intervention e.g. conducting the survey, analysing the survey results, the shared leadership programme etc.
ASF support phone calls throughout process to provide support and share ideas

Provision of ongoing online training sessions for implementers targeted at what's happening next in the programme
Conduct educational meetings
Allows schools to share best practice as well as provide support to one another on various aspects of the programme.

Online meetings allow for ease of collaboration and are time efficient
Support webinars allow for a specific focus on challenging aspects of the process to educate with the objective of a high survey response rate and student-led survey analysis and action plan development
Conduct outreach visits educational
Outreach visits throughout process will allow ASF support provide feedback to schools on their progress. Also enable schools to ask questions and gain support on challenges.
Conduct ongoing training
Support webinars allow for a specific focus on challenging aspects of the process such as to educate on achieving a high survey response rate, student-led survey analysis and action plan development 


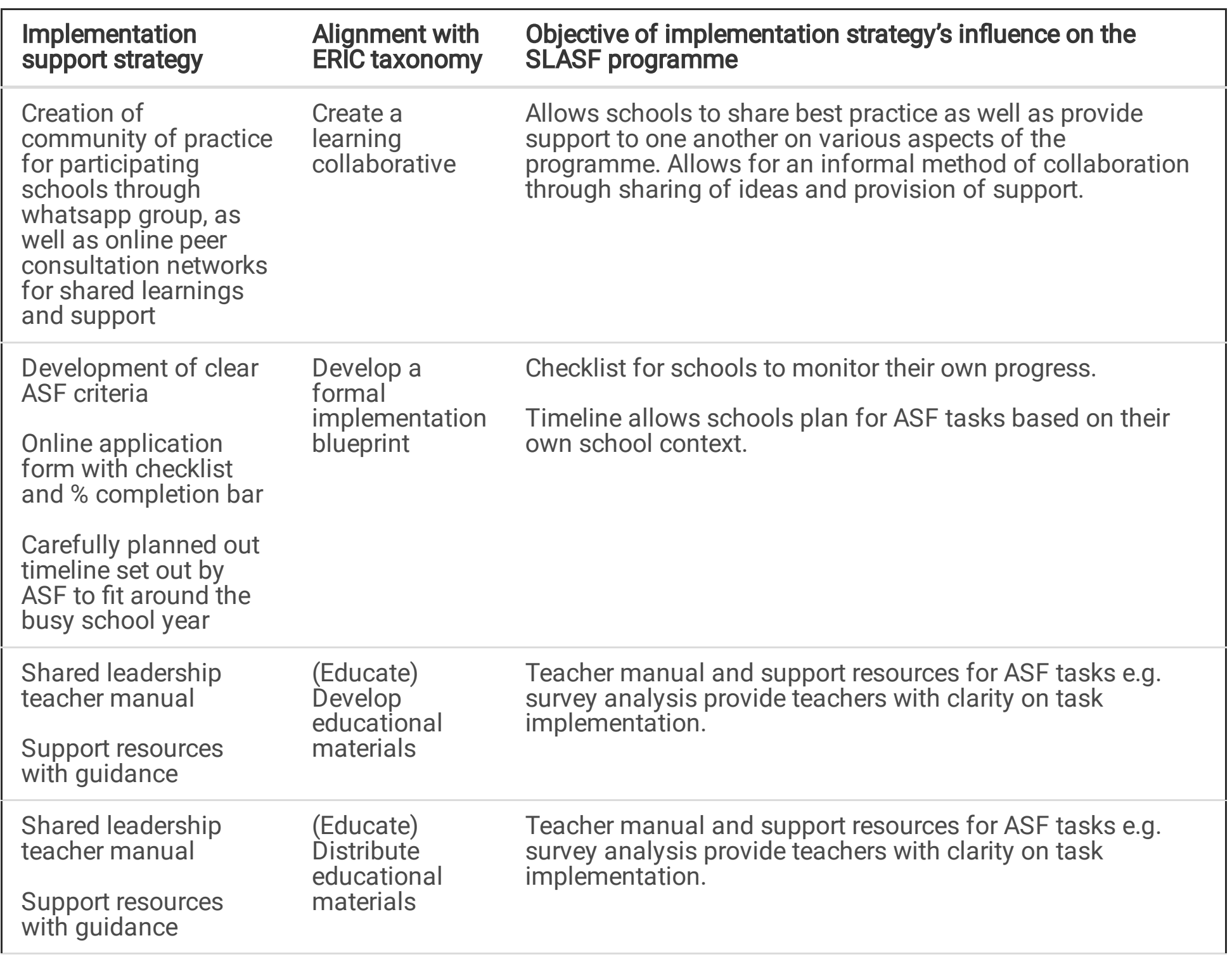




\section{Implementation support strategy}

Recommendation of coordinator as full time and established member of staff

Shared leadership identification of leaders with efficient use of natural leaders in ASF TY class through shared leadership programme

Guidance on identification of strong staff committee

Opt in ASF TY class

Support webinars for champions

Addition of two coordinators instead of one

Recommendation for member of the PE department on the ASF committee

Readiness to engage documents for school management and staff

Eligibility criteria sets out that buy-in from management is essential from start

Facilitation of staff committee meetings at least once per term/allocation of staff hours to staff implementers

Timetabled TY class

Timetabling of two coordinators with ASF class and also other committee members where possible.

\section{Alignment with ERIC taxonomy \\ Objective of implementation strategy's influence on the SLASF programme}

(Plan) Identify and prepare champions
Provides the coordinator with more flexibility and time across the week for ad hoc SLASF related work. Being an established member of staff may carry more weight for getting staff on board for ASF.

The election of leaders by peers allows students identify those they feel are strong leaders in certain areas.

Guidance document on election of staff committee provides school with a blue print of the most appropriate type of staff to be involved.

Opt in ASF TY class facilitates those who are motivated to lead on ASF and help create change for PA in the school.

Support webinars guide implementers throughout various stages of the process and in a step-by-step manner.

A second coordinator will alleviate pressure on main coordinator and prevents start over if that coordinator has to give up the role for some reason.

Access to the PE department is important for aspects of the programme such as the ASW and launch event and having a strong link with staff here will help run events more smoothly.
Obtain formal commitments
Facilitates a commitment to the process from the outset and encourages management and staff to read through all relevant guidance and documents before deciding if it is feasible to run in their school.
Organize

clinician implementation team meetings
Provides staff implementers with an official time to meet to alleviate pressures on already busy staff.

TY class have a time and space to implement the programme, through preparation in class and also an official time allocation for class visits, promotion work etc. Class time gives coordinator a space to meet the group on a regular basis.

Regular contact time with more than just the coordinator alleviates pressure on coordinator and creates a connection between the TYs and other staff committee members. 


\section{Implementation support strategy}

Flexibility in timeline for completion i.e. 3-5 years

Action plan development based on individual school needs

Core components of programme outlined in programme booklet allowing for flexibility around and beyond this checklist
Accreditation visit once per year

ASF support phone calls throughout process to provide support and share ideas
Alignment with

ERIC taxonomy

Promote adaptability

\section{Objective of implementation strategy's influence on the SLASF programme}

Allows schools flexibility in their approach taking up to 5 years for programme completion. Flexible timeline will allow schools for unexpected barriers along the way and to make judgement on length of time required for certain tasks.

Caters for individual school needs e.g. what students in a boys urban school would like may differ from what boys in a rural school.

Flexibility outside core components allows schools implement based on their school context and setting.
Provide ongoing consultation
Provides school with feedback and monitoring on their progress.

Support from ASF throughout process will enable schools to ask questions and gain support on challenges.

\section{Create links with schools at different stages to provide advice to new schools undertaking the programme \\ Shadow other experts}

Inclusion of 'information hub' for schools to communicate ASF using existing effective communication networks and strengths

More efficient branding of ASF such as ASF gear for implementers
Use mass

media
Collaboration between schools facilitates sharing of experiences, ideas and provision of support for each other.
Allows schools utilise their existing strengths in their
methods of communication for ASF were recommended.

Branding of ASF heightens awareness of programme and links activities with the brand.

\section{Discussion}

This study explored the facilitators and barriers to implementation of the SLASF, a two-year WSP for promoting PA in Irish secondary level schools. Identifying facilitators and barriers enables researchers to provide recommendations for implementation strategies (31) and may support those who are intended to lead the programme in the school (51). 
The communication and collaboration within schools was both a facilitator and barrier. When schools used positive communication and collaboration methods such as linking in with other departments, and using various strategies to promote ASF in the school this facilitated implementation. Conversely, poor communication and collaboration between implementers as well as between implementers and other school stakeholders led to poor optimisation of existing strengths and low awareness of ASF in the school. The Finnish Schools on the Move programme has emphasised the need for information and communication within the school community regarding the intervention and these promotional efforts were assisted by staff working groups (52). Additionally, low buy-in and support from staff was linked with the "busyness" of the school. Buy-in and support from teachers has been linked with facilitators for programme implementation in other school-based PA programmes $(53,54)$. Recommendations to support school readiness and improved promotion and communication channels around ASF are to include the introduction of a 'readiness to engage document' for management and staff, include an introductory year and the use of a more flexible 'information hub'.

There was a lack of engagement by some stakeholders, however this was often not due to dissatisfaction with the intervention, rather not having opportunities to be involved. Although a pillar of ASF is inclusivity, being able to fulfil this value was a challenge for schools in trying to include senior and exam year students in activities and events. This aligns with recommendations by Hartwig (2021) that school-based interventions should be more equally distributed among sub populations and should specifically target strategies to meet the needs of older students (55).

Implementation of the programme was limited by the existing strengths of both people and current structures not being optimised. Overall, the best people for specific jobs were not always utilised to their strengths. Lack of empowerment of ASF TY students often emanated from the coordinator being hesitant about certain students enacting elements of the process. This lack of empowerment was also discussed for members of the ASF committee where the coordinator was sometimes reluctant to delegate jobs and share the workload due to being conscious that staff were otherwise busy. However, some barriers were also facilitators (e.g., optimisation of the TY class as enactors of ASF implementation was also a key facilitator in the running of the programme). ASF TY students were heavily involved in programme implementation whereby they promoted ASF, assisted in running events and ASF tasks. This level of work undertaken by the TYs was consistently reported by adult stakeholders as a facilitator in programme implementation and was facilitated by adults providing student empowerment. However, because students did not assign themselves to be in the ASF class, it was a 'lottery' as to the level of enthusiasm the students had about their involvement in running ASF and this varied in schools between year 1 and year 2. Recommendations to overcome some of these challenges are to increase capacity for implementers through an opt-in to the programme for the ASF TY students, to provide more contact timetabled time with committee members and introduce student leadership training to provide students with their roles, responsibilities and expectations of the programme. It has been suggested in previous studies that a greater emphasis on organisational readiness and capacity building are required to facilitate the sustainability of evidence-based interventions in schools $(56,57)$.

The capacity to implement the ASF committee was limited when management appointed already busy staff to these roles. As a result, coordinators reported that they felt SLASF was "a one man show" in terms of promotion efforts despite the SLASF intended to be led by an engaged and participatory staff committee 
through a WSA. In primary schools, sustainability of the programme was influenced by the commitment levels of the coordinators (58). However, SLASF coordinators were over-burdened with the workload and it was suggested that sustainability would depend on the strength of support structure around them. Evidence from previous studies suggests moving away from a reliance on one person and having a solid, strong and supportive staff committee (58) embedded within a supportive school climate as crucial for successful implementation, expansion and sustainability of WSPs (12). Strategies that may overcome this challenge is the provision of guidance on identifying and appointing a strong staff committee who should be facilitated by management to meet at least once per school term. Additionally, the coordinator should have the capacity to lead on the programme through being a full-time established member of staff with limited leadership commitments outside of ASF in their working week. A school-based PA intervention in Australia provides a half day per week funding for the PA champion, highlighting the importance of this time allocation for successful implementation (59). Moreover, the promotion of strong, continuous executive support and staff engagement support has been recommended to assist in the sustainability of school-based programmes (60)

Across all three schools, time for change was a facilitator for SLASF. This was evident in schools in the second year where coordinators were more relaxed about the process, recognising that patience was part of the journey and to appreciate the "small wins". Despite the interference of COVID-19 school closures on programme implementation, coordinators acknowledged that they didn't feel they would deserve flag success and even in a "normal year", two years was not enough time for it to be embedded or be meaningful. The research team recommended having a successful whole school approach (WSA) within the boundaries of the school prior to adding the local community and parental elements. Therefore, it is recommended to have a readiness year making the SLASF a minimum of 3 years, also allowing schools flexibility in their approach taking up to 5-years to get through all components of the programme where required. The addition of a readiness year included a commitment to change and could garner confidence in their collective abilities to implement programme requirements (61). The flexibility in the SLASF timeline completion reflects the idea that school-based PA promoting programmes should move away from a one-size-fits-all approach $(62,63)$ and integrate these approaches into the realities of the school system, providing context specific support (64). Similar practices have been reported in other WSPs, such as the Finnish Schools on the Move programme, where schools may take five years to implement the programme (65).

The student leadership aspect of the programme was linked with the student voice component of SLASF. All schools had a high response rate (average 61\%) from the whole school survey and in one school the ASF TYs undertook a verification of results by going around to various classes. However, it appeared that there was not enough emphasis or awareness from implementers as to the importance of both the whole school survey and action plan development for the student leadership and student voice components of ASF. Student voice also posed challenges when ideas were rejected by school management. The importance of involving both children and adults to initiate change for topics that affect their lives has previously been advocated for (66). Furthermore, teachers need to create opportunities for students to make enabling moves in the process of achieving student agency (67). However, it was emphasised by Treseder (1997) that student agency does not occur in a sequence and depends on the appropriateness of the circumstance (68). In one school, the ASF TYs required adult intervention on their first day of running the action plan, therefore highlighting that children need to be supported and guided by adults in leadership and decision making processes and not solely a 'children 
in charge' approach (66). This data suggests that capacity building to enhance the student leadership and student voice aspects of the programme could assist in the sustainability of running such a WSP. The addition of a shared leadership programme for the ASF TY class is therefore recommended. This could provide students with the knowledge about leadership, prepare them as a team to achieve their goals and share the workload with the ASF coordinator and staff committee (69).

\section{Limitations}

These findings cannot be generalised to all secondary level schools in Ireland as there were three types of schools (girls urban, mixed urban and mixed rural) partaking in this research study. Future studies should seek participants from other school types such as boys rural and boys urban. Additionally, there was the possibility of desirable responses from programme implementers due to the potential fear of showing weaknesses in their performance to date. However, the researchers placed an emphasis on the importance of sharing their challenges in order to improve the programme and implementers were usually forthcoming about the barriers they faced. Due to COVID-19 restrictions, schools worked remotely and interview data from management, committee members and ASF TYs was not possible to obtain during that time. However, both communication and data collection did continue with the coordinators through telephone communications throughout these restrictions.

\section{Conclusions}

Through guidance from Powell (2017) on the identification of implementation strategies and in alignment with the ERIC taxonomy, we have provided recommendations for implementation support strategies for the SLASF. The facilitators and barriers identified in this study led to the recommendations such as an ASF TY class shared leadership training programme and the addition of an introductory "try it out" year to identify if schools want to proceed with the SLASF programme. This study reaffirmed the notion that second level schools are complex environments thus, exploring this complexity with end-users and identifying implementation strategies is critical to increase the likelihood of programme success. There were facilitators and barriers to SLASF implementation in schools related to intervention design, organisational and interpersonal factors. These findings build on existing literature regarding the implementation of school-based PA promoting interventions through a WSA requiring multiple stakeholder engagement. Future research is required to conduct an implementation outcome evaluation on these implementation support strategies to examine each strategy regarding key implementation indicators including fidelity, adoption, acceptability, and adherence.

\section{Abbreviations}

PA: Physical Activity

MVPA: Moderate-to-vigorous-physical-activity

ISPAH: International Society for Physical Activity and Health

WSP: Whole-of-school-programme

Page 19/30 
WSA: Whole-of-school-approach

GAPPA: Global Action Plan on Physical Activity

ASF: Active School Flag

DES: Department of Education and Skills

SLASF: Secondary Level Active School Flag Programme

TY: Transition Year

CFIR: Consolidated Framework for Implementation Research

ERIC: Expert Recommendations for Implementing Change

SRQR: Standards for Reporting Qualitative Research

TA: Thematic Analysis

ASW: Active School's Week

IS: Inner Setting

OS: Outer \setting

IC: Intervention Characteristics

COI: Characteristics of Individuals

POI: Process of Implementation

\section{Declarations}

\section{Ethics approval and consent to participate}

The study has been approved by the research ethics committee of the Faculty of Education and Health Sciences, University of Limerick (ref no. 2018/10/18_EHS). Study participants provided written informed consent and their anonymity and confidentiality was ensured. Study participants under the age of 16 provided written parental consent to participate.

Consent for publication

Not applicable

\section{Availability of data and material}

The data (transcripts) used during this study are available from the corresponding author on request.

\section{Competing interests}


The authors declare no competing interests with regard to this study

\section{Funding}

This study was made possible by the support of The University of Limerick,

Mayo Education Centre, Healthy Ireland, and St. Vincent's Charity.

\section{Authors' contributions}

FM: Conceptualization and design of study, acquisition and analysis of data, drafting and revision of manuscript; KN: Conceptualization and design of study, acquisition and analysis of data, revision of manuscript; JC: Acquisition and analysis of data, revision of manuscript; CG: Analysis of data, revision of manuscript; DS: Acquisition of data, revision of manuscript; CN: Conceptualization of study, revision of manuscript; DOS: Co-PI of the project, conceptualization of study, revision of manuscript; CW: Co-PI of the project, funding acquisition, conceptualization and design of study, acquisition and analysis of data, revision of manuscript. All authors approved the final manuscript.

\section{Acknowledgements}

The authors wish to thank the students, coordinators, teachers and management from the participating schools. The authors would also like to thank the ASF developers for their support throughout this research process. Thanks also to EE, MC, JC, KV for their assistance in data collection.

\section{Author's information}

Fiona McHale: fiona.mchale@ul.ie

Kwok Ng: kwok.ng@ul.ie

Jemima Cooper: jac208@bath.ac.uk

Dylan Scanlon: dylan.scanlon@dcu.ie

Caera Grady: caera.grady@ul.ie

Catherine Norton: catherine.norton@ul.ie

Donal O’Shea: info@dosheaendo.ie

Catherine Woods: catherine.woods@ul.ie

\section{References}

1. Bull FC, Al-Ansari SS, Biddle S, Borodulin K, Buman MP, Cardon G, et al. World Health Organization 2020 guidelines on physical activity and sedentary behaviour. British Journal of Sports Medicine. 2020;54(24):1451. 
2. Guthold R, Stevens GA, Riley LM, Bull FC. Global trends in insufficient physical activity among adolescents: a pooled analysis of 298 population-based surveys with 1.6 million participants. The Lancet Child \& Adolescent Health. 2020;4(1):23-35.

3. Biddle SJH, Ciaccioni S, Thomas G, Vergeer I. Physical activity and mental health in children and adolescents: An updated review of reviews and an analysis of causality. Psychology of Sport and Exercise. 2019;42:146-55.

4. Cristi-Montero C, Chillón P, Labayen I, Casajus JA, Gonzalez-Gross M, Vanhelst J, et al. Cardiometabolic risk through an integrative classification combining physical activity and sedentary behavior in European adolescents: HELENA study. Journal of sport and health science. 2019;8(1):55-62.

5. Eime RM, Young JA, Harvey JT, Charity MJ, Payne WR. A systematic review of the psychological and social benefits of participation in sport for children and adolescents: informing development of a conceptual model of health through sport. International Journal of Behavioral Nutrition and Physical Activity. 2013;10(1):98.

6. Hayes G, Dowd KP, MacDonncha C, Donnelly AE. Tracking of Physical Activity and Sedentary Behavior From Adolescence to Young Adulthood: A Systematic Literature Review. J Adolesc Health. 2019;65(4):446-54.

7. Dobbins M, Husson H, DeCorby K, LaRocca RL. School-based physical activity programs for promoting physical activity and fitness in children and adolescents aged 6 to 18. Cochrane Database Syst Rev. 2013;2013(2):Cd007651.

8. Kriemler S, Meyer U, Martin E, van Sluijs EM, Andersen LB, Martin BW. Effect of school-based interventions on physical activity and fitness in children and adolescents: a review of reviews and systematic update. $\mathrm{Br} \mathrm{J}$ Sports Med. 2011;45(11):923-30.

9. Borde R, Smith JJ, Sutherland R, Nathan N, Lubans DR. Methodological considerations and impact of school-based interventions on objectively measured physical activity in adolescents: a systematic review and meta-analysis. Obesity reviews : an official journal of the International Association for the Study of Obesity. 2017;18(4):476-90.

10. Love R, Adams J, van Sluijs EMF. Are school-based physical activity interventions effective and equitable? A meta-analysis of cluster randomized controlled trials with accelerometer-assessed activity. Obes Rev. 2019;20(6):859-70.

11. Daly-Smith A, Quarmby T, Archbold VSJ, Corrigan N, Wilson D, Resaland GK, et al. Using a multistakeholder experience-based design process to co-develop the Creating Active Schools Framework. Int J Behav Nutr Phys Act. 2020;17(1):13.

12. Naylor P-J, Nettlefold L, Race D, Hoy C, Ashe MC, Wharf Higgins J, et al. Implementation of school based physical activity interventions: A systematic review. Preventive Medicine: An International Journal Devoted to Practice and Theory. 2015;72:95-115. 
13. ISPAH. International Society for Physical Activity and Health: Eight Best Investments that work for Physical Activity International Society for Physical Activity and Health; 2020 November 2020.

14. WHO. Global Action plan on physical activity 2018-2030: more active people for a healthier world. World Health Organisation. 2018;Geneva.

15. Woods CB, Volf K, Kelly L, Casey B, Gelius P, Messing S, et al. The evidence for the impact of policy on physical activity outcomes within the school setting: A systematic review. J Sport Health Sci. 2021;10(3):26376.

16. The Active School Flag. https://activeschoolflag.ie 2021 [cited 2021 25/7/221].

17. Ng KW, McHale F, Cotter K, O’Shea D, Woods C. Feasibility study of the secondary level Active School Flag programme: Study Protocol. Journal of Functional Morphology and Kinesiology. 2019;4(1):16.

18. Belton S, Britton Ú, Murtagh E, Meegan S, Duff C, McGann J. Ten Years of 'Flying the Flag': An Overview and Retrospective Consideration of the Active School Flag Physical Activity Initiative for Children-Design, Development \&amp; Evaluation. Children. 2020;7(12).

19. Clerkin A. Personal development in secondary education: the Irish Transition Year. education policy analysis archives. 2012;20:38.

20. Baranowski T, Stables G. Process evaluations of the 5-a-day projects. Health Education \& Behavior. 2000;27(2):157-66.

21. Mitra D. Student voice in secondary schools: the possibility for deeper change. Journal of Educational Administration. 2018;56(5):473-87.

22. van Sluijs EM, McMinn AM, Griffin SJ. Effectiveness of interventions to promote physical activity in children and adolescents: systematic review of controlled trials. BMJ. 2007;335(7622):703.

23. Durlak JA, DuPre EP. Implementation matters: a review of research on the influence of implementation on program outcomes and the factors affecting implementation. Am J Community Psychol. 2008;41(3-4):327-50.

24. Birken SA, Powell BJ, Presseau J, Kirk MA, Lorencatto F, Gould NJ, et al. Combined use of the Consolidated Framework for Implementation Research (CFIR) and the Theoretical Domains Framework (TDF): a systematic review. Implementation Science. 2017;12(1):2.

25. Shortell SM, Marsteller JA, Lin M, Pearson ML, Wu SY, Mendel P, et al. The role of perceived team effectiveness in improving chronic illness care. Med Care. 2004;42(11):1040-8.

26. Damschroder LJ, Aron DC, Keith RE, Kirsh SR, Alexander JA, Lowery JC. Fostering implementation of health services research findings into practice: a consolidated framework for advancing implementation science. Implement Sci. 2009;4:50. 
27. Birken SA, Powell BJ, Shea CM, Haines ER, Alexis Kirk M, Leeman J, et al. Criteria for selecting implementation science theories and frameworks: results from an international survey. Implementation Science. 2017;12(1):124.

28. Kirk MA, Kelley C, Yankey N, Birken SA, Abadie B, Damschroder L. A systematic review of the use of the Consolidated Framework for Implementation Research. Implementation Science. 2016;11(1):72.

29. French SD, Green SE, O'Connor DA, McKenzie JE, Francis JJ, Michie S, et al. Developing theory-informed behaviour change interventions to implement evidence into practice: a systematic approach using the Theoretical Domains Framework. Implementation Science. 2012;7(1):38.

30. Powell BJ, McMillen JC, Proctor EK, Carpenter CR, Griffey RT, Bunger AC, et al. A compilation of strategies for implementing clinical innovations in health and mental health. Med Care Res Rev. 2012;69(2):123-57.

31. Wolfenden L, Foy R, Presseau J, Grimshaw JM, Ivers NM, Powell BJ, et al. Designing and undertaking randomised implementation trials: guide for researchers. BMJ. 2021;372:m3721.

32. Proctor EK, Powell BJ, McMillen JC. Implementation strategies: recommendations for specifying and reporting. Implementation Science. 2013;8(1):139.

33. Powell BJ, Waltz TJ, Chinman MJ, Damschroder LJ, Smith JL, Matthieu MM, et al. A refined compilation of implementation strategies: results from the Expert Recommendations for Implementing Change (ERIC) project. Implementation Science. 2015;10(1):1-14.

34. Nilsen P. Making sense of implementation theories, models and frameworks. Implementation Science. 2015;10(1):53.

35. Sparkes AC, Smith B. Qualitative research methods in sport, exercise and health: From process to product. New York, NY, US: Routledge/Taylor \& Francis Group; 2014. vii, 279-vii, p.

36. Hamilton AB, Finley EP. Qualitative methods in implementation research: An introduction. Psychiatry Research. 2019;280:112516.

37. Carey MA, Smith MW. Capturing the group effect in focus groups: A special concern in analysis. Qualitative health research. 1994;4(1):123-7.

38. Gibson F. Conducting focus groups with children and young people: strategies for success. Journal of research in nursing. 2007;12(5):473-83.

39. Wolfenden L, Nathan NK, Sutherland R, Yoong SL, Hodder RK, Wyse RJ, et al. Strategies for enhancing the implementation of school-based policies or practices targeting risk factors for chronic disease. The Cochrane database of systematic reviews. 2017;11(11):CD011677-CD.

40. Creswell JW, Clark VLP. Designing and conducting mixed methods research: Sage publications; 2017. 
41. O’Brien BC, Harris IB, Beckman TJ, Reed DA, Cook DA. Standards for reporting qualitative research: a synthesis of recommendations. Academic Medicine. 2014;89(9):1245-51.

42. Braun V, Clarke V. Reflecting on reflexive thematic analysis. Qualitative Research in Sport, Exercise and Health. 2019;11(4):589-97.

43. Nowell LS, Norris JM, White DE, Moules NJ. Thematic analysis: Striving to meet the trustworthiness criteria. International journal of qualitative methods. 2017;16(1):1609406917733847.

44. Braun V, Clarke V. To saturate or not to saturate? Questioning data saturation as a useful concept for thematic analysis and sample-size rationales. Qualitative research in sport, exercise and health. 2021;13(2):201-16.

45. Fereday J, Muir-Cochrane E. Demonstrating rigor using thematic analysis: A hybrid approach of inductive and deductive coding and theme development. International journal of qualitative methods. 2006;5(1):80-92.

46. Perry C, Thurston M, Green K. Involvement and Detachment in Researching Sexuality: Reflections on the Process of Semistructured Interviewing. Qualitative health research. 2004;14(1):135-48.

47. Lincoln YS, Guba EG. Establishing trustworthiness. Naturalistic inquiry. 1985;289(331):289-327.

48. DeCuir-Gunby JT, Marshall PL, McCulloch AW. Developing and Using a Codebook for the Analysis of Interview Data: An Example from a Professional Development Research Project. Field Methods. 2010;23(2):136-55.

49. MacPhail A, Tannehill D, Ataman R. The role of the critical friend in supporting and enhancing professional learning and development. Professional Development in Education. 2021:1-14.

50. Powell BJ, Beidas RS, Lewis CC, Aarons GA, McMillen JC, Proctor EK, et al. Methods to Improve the Selection and Tailoring of Implementation Strategies. J Behav Health Serv Res. 2017;44(2):177-94.

51. Sutherland RL, Campbell EM, Lubans DR, Morgan PJ, Nathan NK, Wolfenden L, et al. The Physical Activity 4 Everyone Cluster Randomized Trial: 2-Year Outcomes of a School Physical Activity Intervention Among Adolescents. Am J Prev Med. 2016;51(2):195-205.

52. Haapala HL, Hirvensalo MH, Laine K, Laakso L, Hakonen H, Lintunen T, et al. Adolescents' physical activity at recess and actions to promote a physically active school day in four Finnish schools. Health Educ Res. 2014;29(5):840-52.

53. Chalkley AE, Routen AC, Harris JP, Cale LA, Gorely T, Sherar LB. A retrospective qualitative evaluation of barriers and facilitators to the implementation of a school-based running programme. BMC Public Health. 2018;18(1):N.PAG-N.PAG.

54. Sebire SJ, Banfield K, Jago R, Edwards MJ, Campbell R, Kipping R, et al. A process evaluation of the PLANA intervention (Peer-Led physical Activity iNtervention for Adolescent girls). BMC public health. 2019;19(1):113. 
55. Hartwig TB, Sanders T, Vaconcellos D, Noetel M, Parker PD, Lubans DR, et al. School-based interventions modestly increase physical activity and cardiorespiratory fitness but are least effective for youth who need them most: an individual participant pooled analysis of 20 controlled trials. British Journal of Sports Medicine. 2021:bjsports-2020-102740.

56. McLoughlin GM, Candal P, Vazou S, Lee JA, Dzewaltowski DA, Rosenkranz RR, et al. Evaluating the implementation of the SWITCH® school wellness intervention and capacity-building process through multiple methods. International Journal of Behavioral Nutrition and Physical Activity. 2020;17(1):1-18.

57. Bice MR, Brown SL, Parry T. Retrospective evaluation of factors that influence the implementation of CATCH in southern Illinois schools. Health Promot Pract. 2014;15(5):706-13.

58. McMullen JM, Ní Chróinín D, lannucci C. What happened next? Exploring the sustainability of a whole-ofschool physical activity initiative. International Journal of Health Promotion and Education. 2020:1-10.

59. Sutherland R, Campbell E, Nathan N, Wolfenden L, Lubans DR, Morgan PJ, et al. A cluster randomised trial of an intervention to increase the implementation of physical activity practices in secondary schools: study protocol for scaling up the Physical Activity 4 Everyone (PA4E1) program. BMC Public Health. 2019;19(1):883.

60. Shoesmith A, Hall A, Wolfenden L, Shelton RC, Powell BJ, Brown H, et al. Barriers and facilitators influencing the sustainment of health behaviour interventions in schools and childcare services: a systematic review. Implementation Science. 2021;16(1):62.

61. Weiner BJ. A theory of organizational readiness for change. Implementation Science. 2009;4(1):67.

62. Finegood DT, Johnston LM, Steinberg M, Matteson CL, Deck P. Complexity, systems thinking, and health behavior change. Health Behavior Change in Populations. 2014:435-58.

63. Norman A, Nyberg G, Elinder LS, Berlin A. One size does not fit all-qualitative process evaluation of the Healthy School Start parental support programme to prevent overweight and obesity among children in disadvantaged areas in Sweden. BMC Public Health. 2016;16:37.

64. van Sluijs EM, Ekelund U, Crochemore-Silva I, Guthold R, Ha A, Lubans D, et al. Physical activity behaviours in adolescence: current evidence and opportunities for intervention. The Lancet. 2021.

65. Blom A, Tammelin T, Laine K, Tolonen H. Bright spots, physical activity investments that work: the Finnish Schools on the Move programme. BMJ Publishing Group Ltd and British Association of Sport and Exercise Medicine; 2018.

66. Hart RA. Children's participation: From tokenism to citizenship. 1992.

67. Scanlon D, Connolly C. Teacher agency and learner agency in teaching and learning a new school subject, Leaving Certificate Computer Science, in Ireland: Considerations for teacher education. Computers \& Education. 2021;174:104291. 
68. Treseder P, Smith P. Empowering Children \& Young People: Training Manual Save the Children London. 1997.

69. Fransen K, Delvaux E, Mesquita B, Van Puyenbroeck S. The Emergence of Shared Leadership in Newly Formed Teams With an Initial Structure of Vertical Leadership: A Longitudinal Analysis. The Journal of Applied Behavioral Science. 2018;54(2):140-70.

\section{Figures}

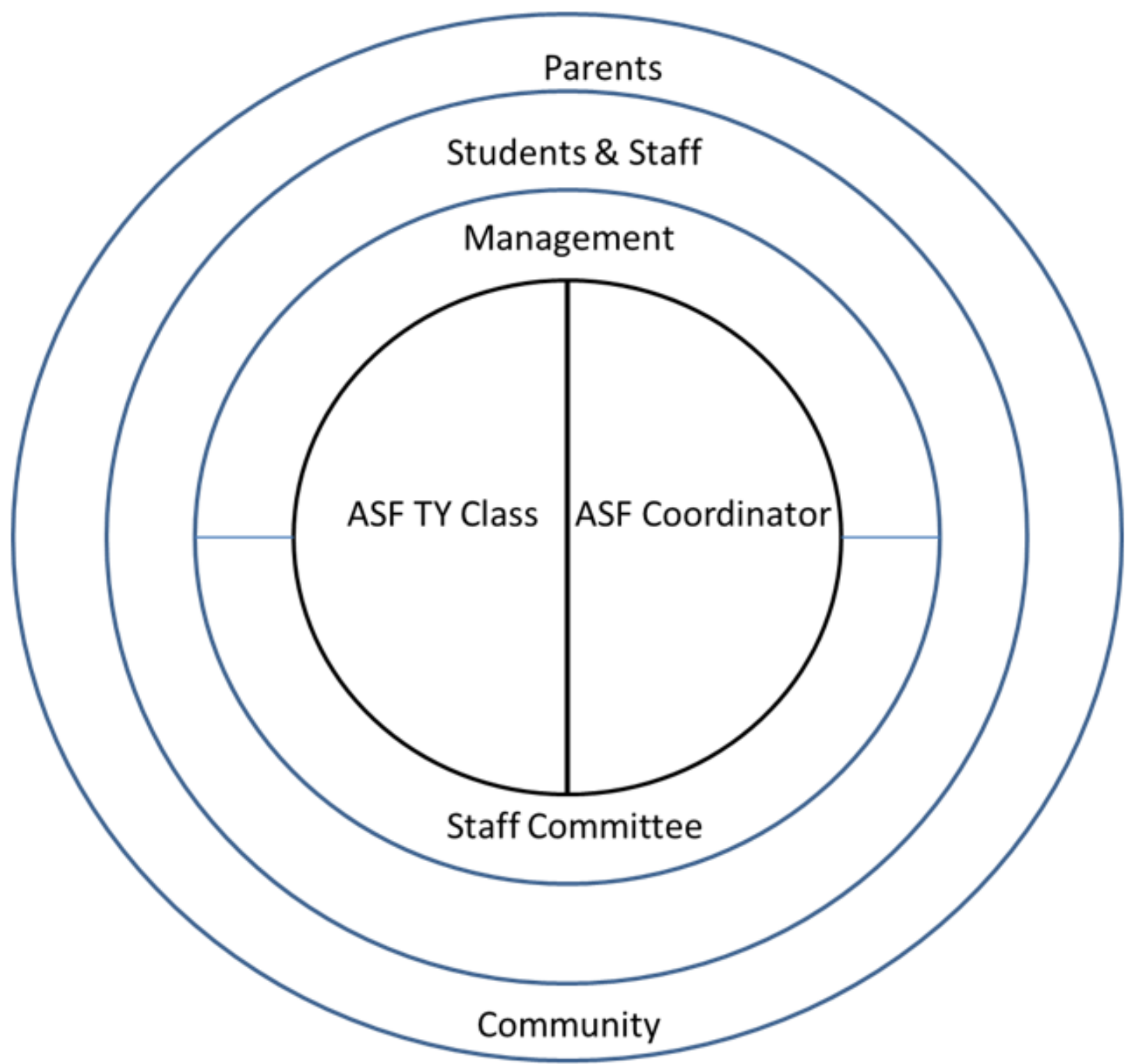

Figure 1

Implementation of the Secondary Level Active School Flag programme 


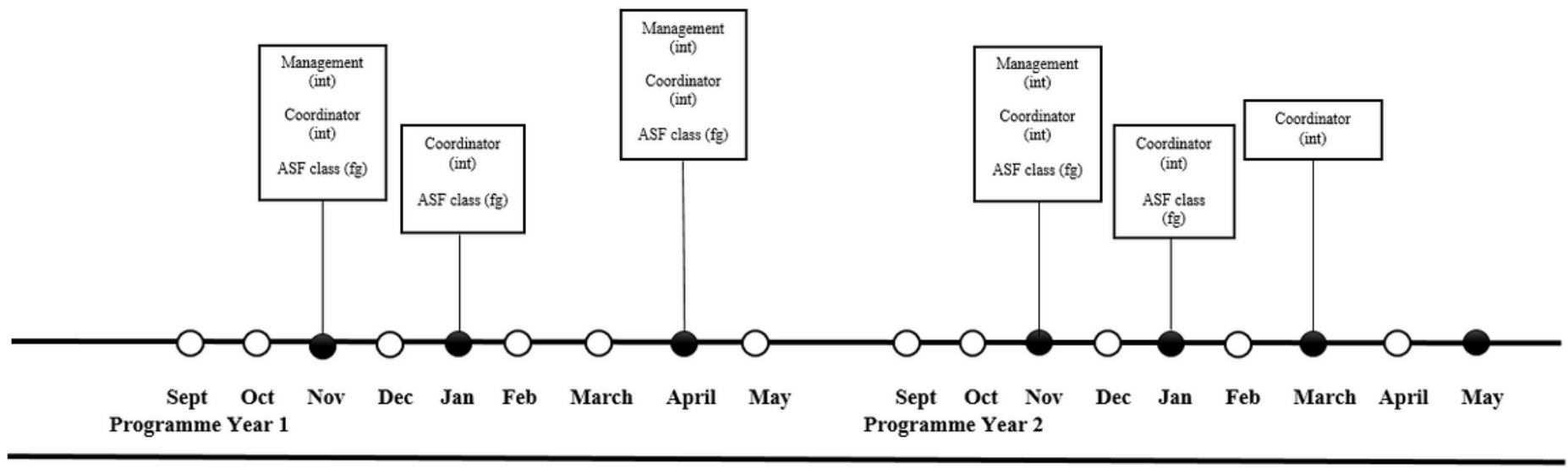

Figure 2

Data collection timeline of interviews (int) and focus groups ( $\mathrm{fg}$ ) that took place 


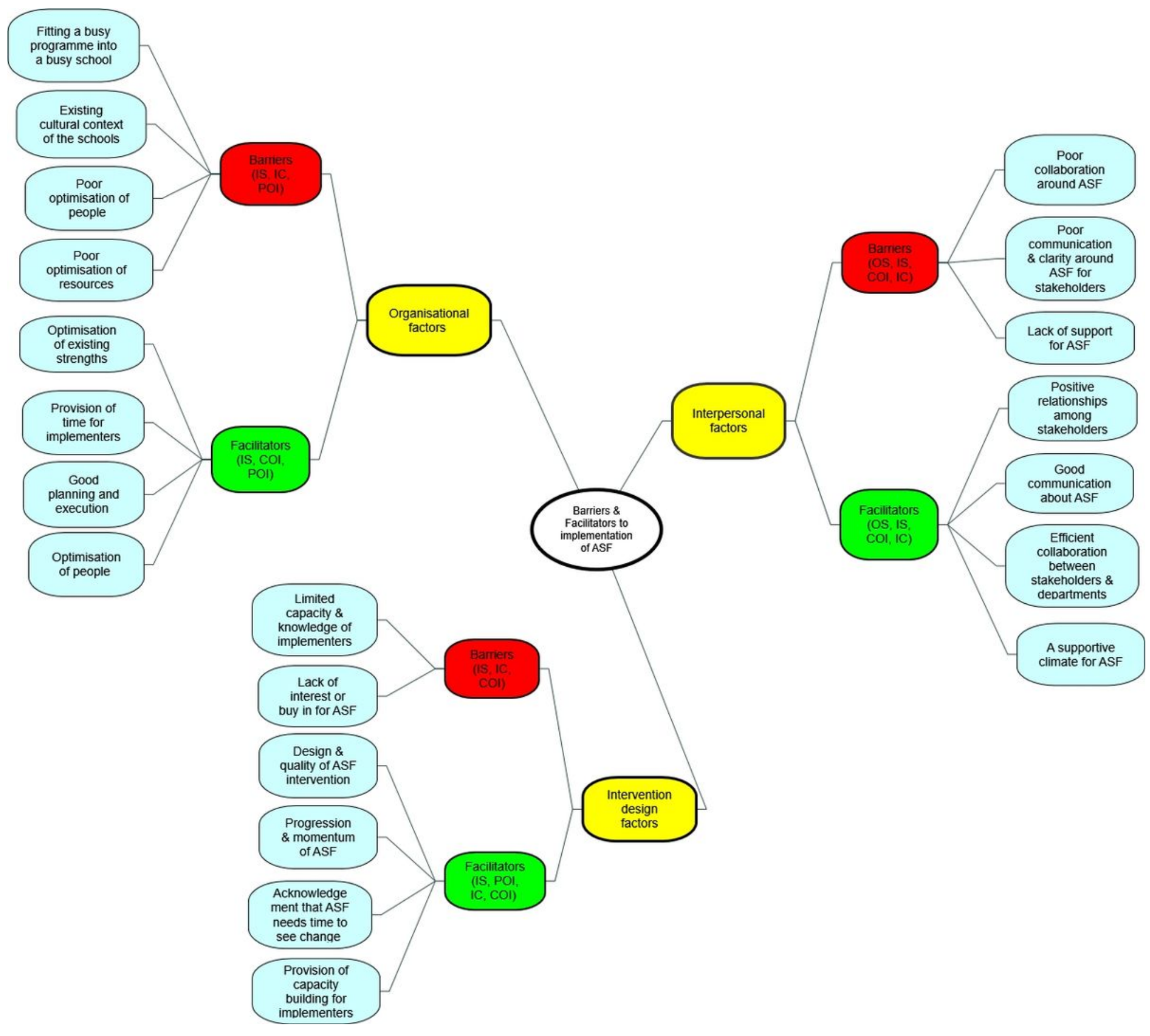

Figure 3

Thematic map illustrating facilitators and barriers to implementation of the Secondary Level Active School Flag Programme including CFIR domains they intersect i.e. inner setting (IS), outer setting (OS), intervention characteristics (IC), characteristics of individuals (COI) and process of implementation (POI)

\section{Supplementary Files}

This is a list of supplementary files associated with this preprint. Click to download.

- Additionalfile1 Interviewandfocusgroupguideexcerpts.docx

- Additionalfile2SRQRchecklist.docx 
- Additionalfile3ScreenshotofcodingonPadlet.docx 